\title{
Investigando a compreensão conceitual em física de alunos de graduação em cursos de ciências, engenharias e matemática
}

Investigating conceptual understanding in physics from undergraduate students in science, engineering and mathematics

\author{
Matheus Pinheiro Quibao ${ }^{1}$, Angélica Carrillo Silva ${ }^{10}$, Nicoly Soares de Almeida ${ }^{1}$, Rosanna Maria \\ Araújo Andrade Silva ${ }^{1}$, Sérgio Ricardo Muniz ${ }^{10}$, Fernando Fernandes Paiva*1@ \\ ${ }^{1}$ Universidade de São Paulo, Instituto de Física de São Carlos, São Carlos, SP, Brasil
}

\begin{abstract}
Recebido em 10 de Setembro, 2018. Revisado em 26 de Setembro, 2018. Aceito em 28 de Setembro, 2018.
\end{abstract}
\begin{abstract}
O ganho de aprendizado conceitual em disciplinas introdutórias de Física para alunos ingressantes na universidade, submetidos a diferentes abordagens metodológicas, foi medido com um instrumento padronizado internacionalmente reconhecido. O estudo envolveu 599 estudantes de engenharia, física e matemática do campus da USP de São Carlos, no primeiro semestre do ano de 2017. Dentre os principais resultados, está o perfil de conhecimento conceitual básico de entrada desses estudantes e sua correlação com o processo de seleção no vestibular. Avaliamos esses resultados e os ganhos conceituais obtidos dentro das diferentes turmas e cursos do campus, apresentando uma comparação direta e quantitativa dos desempenhos de turmas tradicionais com turmas que fazem uso de metodologias ativas. Esses resultados são também comparados com dados de estudos nacionais e internacionais, contribuindo para preencher uma lacuna ainda presente na literatura nacional, carente de estudos quantitativos em larga escala nessa área. Pudemos confirmar que turmas envolvidas com metodologias ativas de aprendizagem apresentam maior ganho conceitual ao fim do curso, em concordância com a literatura internacional, obtendo-se neste estudo, em média, um ganho normalizado duas vezes maior.
\end{abstract}

Palavras-chave: FCI, Mecânica, Ensino de Física, Ensino Superior.

\begin{abstract}
The gain of conceptual learning in introductory Physics of incoming students at the university, submitted to different methodological approaches, was measured with a standardized and internationally recognized instrument. The study involved 599 engineering, physics and mathematics students from São Carlos campus of the University of São Paulo (USP), during the first semester of 2017. Among the main results is the basic conceptual knowledge profile of these students and their correlation with the admission process. We evaluate these results and the conceptual gains obtained within the different classes and courses of the campus, presenting a direct and quantitative comparison of the performances of traditional classes with classes that make use of active learning methodologies. These results are compared with data from national and international studies, contributing to fill a gap still present in the national literature, lacking large-scale quantitative studies in this area. We were able to confirm that classes involved with active learning methodologies present greater conceptual gain at the end of the course, in agreement with the international literature, obtaining in this study, on average, a normalized gain two times higher.

Keywords: FCI, Mechanics, Physics Teaching, Graduate Studies.
\end{abstract}

\section{Introdução}

A preocupação com o aprendizado crítico e significativo dos alunos de graduação em ciências, e especificamente em Física, não é algo novo, mas tem adquirido um caráter cada vez mais científico nas últimas décadas, no sentido de se estabelecer métricas objetivas e quantitativas que favoreçam o desenvolvimento de modelos e permitam a comparação entre diferentes metodologias de ensino. Os primeiros passos surgiram ainda em meados da década de 80 , a partir de resultados $[1,2]$ mostrando que

*Endereço de correspondência: fernando.paiva@usp.br mesmo estudantes com bom desempenho nas disciplinas de Física (medido em avaliações convencionais) tendem a permanecer com fortes ideias do "senso comum", ou concepções alternativas, que são inconsistentes com conceitos Newtonianos da Mecânica, que muitos estudantes sabem recitar mas raramente compreendem. Isso prejudica a performance e o progresso desses estudantes nesta área de estudo [1-3], sobretudo no Ensino Superior, onde não basta "saber a fórmula". Nesse contexto, Hestenes, Wells e Swackhamer desenvolveram um teste denominado Force Concept Inventory (FCI) [3], que nas últimas décadas tem sido extensivamente usado em inúmeras 
instituições ao redor do mundo [4-13] para medir o ganho conceitual de estudantes em Física Básica. Mais especificamente, seu objetivo principal é testar o entendimento conceitual da mecânica Newtoniana contra os conceitos do senso comum, priorizando as causas e consequências do movimento, em torno do conceito de força.

Desde a sua introdução, o FCI segue uma metodologia de aplicação em dois momentos: no início (Pré-Teste) e no final (Pós-Teste) das disciplinas introdutórias de Física, sendo o Pré-Teste para determinar a linha de base e o Pós-Teste para calcular o ganho conceitual dos estudantes. Os estudos com esse instrumento têm revelado, de forma consistente [7], que nos cursos baseados apenas em metodologias tradicionais, independentemente dos professores e instituições de ensino, o ganho no aprendizado conceitual dos alunos é tipicamente muito pequeno [14]. Esses resultados indicam que em um curso tradicional os estudantes essencialmente não mudam a maneira como entendem os fenômenos físicos, mesmo quando isso é inconsistente com as ideias Newtonianas e o formalismo matemático que eles mesmo aplicam na resolução dos problemas. Em outras palavras, os alunos aprendem algoritmos e fórmulas, mas não aprendem os princípios e ideias fundamentais por trás daqueles fenômenos, nem mudam a sua forma de pensar. Esses resultados do FCI, juntamente com outros estudos similares realizados ao longo das décadas de 80 e 90, deram início a um intenso debate e questionamento acerca da eficácia das metodologias de ensino tradicionalmente adotadas nessas disciplinas, com importantes implicações no desenvolvimento e consolidação da área de pesquisa que é hoje internacionalmente reconhecida como Physics Education Research (PER), que conta com uma comunidade ativa de pesquisadores e publicações especializadas [8].

Apesar de não ser o único teste desse tipo, o FCI, juntamente com os primeiros estudos que motivaram seu desenvolvimento [1-3], ajudou a criar uma categoria de testes padronizados baseados em questionários conceituais (concept inventories) que são hoje frequentemente utilizados como instrumentos de pesquisa. No caso específico do FCI, devido ao seu longo histórico e larga aplicação internacional, ele se tornou um importante padrão de referência, sobretudo na avaliação de novas estratégias de ensino na área de física. Apesar disso, há poucos estudos no Brasil usando esse instrumento. Aqueles que existem envolvem amostras relativamente pequenas e tem escopo limitado, geralmente concentrando-se apenas em medir o ganho de determinada metodologia. Por conta disso, não há dados suficientes para traçar um perfil dos estudantes nas universidades brasileiras, nem entender sua dinâmica diante de novas estratégias de ensino. Um dos objetivos desse trabalho, portanto, é contribuir no sentido de traçar o perfil dos estudantes das áreas de exatas no campus da USP em São Carlos, que inclui uma representativa população de estudantes de física, engenharia e matemática.

Tradicionalmente, os cursos na área de exatas seguem um formato bastante convencional de aulas expositivas, nas quais o aluno costuma ser, muitas vezes, mero espectador e não é usualmente estimulado a confrontar os seus conceitos pré-estabelecidos nas experiências cotidianas [1]. Com o surgimento de novas estratégias de ensino utilizando metodologias centradas no aluno, que passa a ser estimulado a ter uma postura mais ativa e crítica [7], o FCI tornou-se uma importante ferramenta de avaliação da eficácia dessas novas estratégias. Com ele, tornou-se possível comparar os resultados obtidos por alunos expostos às diferentes metodologias nas mais diversas instituições de ensino [4-7, 10-13].

Um exemplo importante na literatura é o estudo realizado por Richard Hake [7], utilizando dados de mais de seis mil alunos, oriundos tanto do Ensino Superior como do Ensino Médio, comparando metodologias tradicionais e diferentes tipos de metodologias ativas em diferentes instituições de ensino. Nesse estudo, observouse um significativo ganho conceitual de alunos em favor das metodologias ativas, com o uso de diferentes atividades de engajamento interativo dos estudantes em sala de aula. Recentemente, um extensivo meta-estudo [15] revisou detalhadamente 225 estudos (que satisfizeram um conjunto estrito de critérios, dentro de um universo de 642 artigos avaliados) na literatura internacional, em diversas áreas do conhecimento, confirmando a eficácia e importância das metodologias ativas, não só no Ensino de Física. Em um artigo convidado na Proceedings of the National Academy of Sciences dos Estados Unidos, um ganhador do prêmio Nobel de Física comenta esses resultados de forma enfática e contundente [16], levantando até mesmo argumentos éticos que merecem uma reflexão séria e profunda por qualquer um preocupado com o aprendizado de ciências.

O teste FCI é composto por 30 questões de múltipla escolha, estruturado de maneira que os alunos devem escolher uma resposta entre alternativas que, além do conceito (Newtoniano) correto, contém também as ideias do senso comum (ou "distrações não-Newtonianas"). Essas distrações foram cuidadosamente elaboradas, a partir de pesquisas anteriores [2], e são colocadas de maneira a intrigar e instigar os estudantes a criticar suas respostas, podendo deixar mesmo os estudantes que pensam de forma "Newtoniana" inseguros sobre a resposta correta. As questões são todas conceituais, apresentadas numa linguagem não técnica, e não exigem nenhum cálculo, ou mesmo um conhecimento formal de Física, por isso o teste pode ser aplicado em diversos níveis educacionais. A construção das questões pode ser decomposta em 6 dimensões conceituais [3], consideradas importantes para o entendimento da mecânica Newtoniana e centradas ao redor do conceito de força, além das mais frequentes concepções não-Newtonianas (baseadas no senso comum), também previamente determinadas por pesquisas na área de PER. Essas componentes são sondadas e revisitadas ao longo do questionário em diferentes questões, apresentadas em diferentes ordens para minimizar efeitos espúrios na avaliação [3], buscando garantir a consistência das respostas relativas a uma dada dimensão conceitual. 
Os autores sugerem "limiares Newtonianos", indicadores da maneira como o aluno interpreta os conceitos da mecânica, sugerindo que alunos que apresentam resultado em torno de $60 \%$ no FCI se encontram no que chamam de "limiar de entrada" para o pensamento Newtoniano, ou seja, apenas começaram a fazer uso dos conceitos coerentemente em seu raciocínio. Para estudantes que obtêm resultado abaixo de $60 \%$, os autores descrevem que há falhas em seu pensamento quanto a diferenciação de conceitos como velocidade e aceleração e equívocos quanto à origem do movimento e agentes de força em um objeto. Ainda segundo os autores, estudantes abaixo desse limiar teriam um domínio insuficiente de conceitos Newtonianos para resolução eficiente de problemas. Por outro lado, estudantes que apresentam resultados maiores ou iguais a $85 \%$ no teste são considerados como pensadores Newtonianos, tendo atingido o patamar chamado de "limiar de domínio" do pensamento Newtoniano [3].

Dessa maneira, os autores propõem um modelo de três estágios de evolução conceitual, que pode ser dividido da seguinte maneira: o Estágio I é o momento em que os alunos desenvolvem um conceito universal de força e aprendem a identificar agentes ativos e passivos de força, e ao dominar esse estágio, os alunos apresentariam nota mínima de $60 \%$ no FCI; Estágio II é onde os alunos desenvolvem conceitos coerentes da dinâmica, como aceleração e força vetorial; Estágio III representa o total domínio do conceito de interação dos corpos pelo entendimento total da Terceira Lei de Newton [7]. No entanto, como constatado em Savinainen et al. [12], deve-se ressaltar que notas altas no teste não garantem que os estudantes têm total domínio dos conceitos Newtonianos, visto que o FCI é um teste de múltipla-escolha que força o aluno a escolher uma alternativa correta. O que se vê, em alguns casos, é que em situações mais complexas e não-familiares, muitas vezes os estudantes não conseguem aplicar corretamente os conceitos Newtonianos. Além disso, há também outras críticas ao FCI [17-20] e resultados recentes indicam que talvez o teste tenha limitações para avaliar currículos não tradicionais (baseados em livros-textos com sequência didática diferente da usual) [21]. Apesar disso, o teste continua sendo uma boa ferramenta na análise de mudanças metodológicas nas disciplinas de Física que seguem um currículo (sequência didática) tradicional.

Como já mencionamos, embora o FCI tenha sido aplicado em inúmeras universidades de diversos países, sua utilização no Brasil ainda é incipiente e pontual. São poucos os relatos de aplicação do FCI em estudantes brasileiros e, principalmente, a quantidade de alunos avaliada representa um percentual muito pequeno dos estudantes, o que dificulta a análise de eventuais semelhanças ou diferenças com relação aos alunos de outros países. Neste estudo, descrevemos a aplicação desse instrumento nos cursos introdutórios de Física (Física 1) no campus da USP em São Carlos, envolvendo cerca de 600 estudantes de diversos cursos.
Historicamente, as disciplinas introdutórias de Física básica oferecidas nos cursos de graduação no campus de São Carlos têm sido predominantemente baseadas em metodologias tradicionais de ensino, com predomínio de aula expositiva e um número relativamente grande de horas em sala de aula (tipicamente 6 horas por semana). Além das aulas expositivas, é também sugerida a realização de lista de exercícios e horários de monitoria, com provas ao final do semestre para avaliar o desempenho dos alunos. Nos últimos anos, visando a adequação dessas disciplinas às metodologias mais modernas e atuais, em consonância com as recentes pesquisas e resultados na área de PER, após um longa e intensa discussão no Instituto de Física de São Carlos (IFSC), implementou-se um projeto de mudança da grade curricular com redução da carga horária dentro de sala de aula, e maior flexibilização na oferta de disciplinas e caminhos de formação durante o bacharelado em Física.

No caso particular das disciplinas do ciclo básico (primeiro ano de graduação), que são oferecidas aos diversos cursos do campus, as mudanças foram mais profundas. Elas passaram a utilizar, de maneira complementar, o método de instrução por pares [14, 22], com incorporação de atividades de discussão e trabalho em grupo, em sala de aula, para resolução de situações-problemas de caráter conceitual e prático [23], e sala de aula invertida [24], com a introdução de exercícios online para ser resolvidos (e entregues) antes das aulas expositivas, visando o melhor aproveitamento do tempo em sala de aula. No caso dos exercícios online, os mesmos ainda eram utilizados para fixação do conteúdo discutido em sala de aula. A metodologia utilizada nos exercícios online é, sobretudo, formativa e não apenas avaliativa, tendo como principal propósito estimular os alunos a virem melhor preparados para as discussões em sala de aula e, no caso dos exercícios pós-aula, oferecer um feedback rápido e mais específico sobre conceitos que exigem maior atenção, na resolução de problemas (típicos dos livros-textos e listas de exercícios). Diferentemente do que ocorre nas abordagens mais tradicionais, nas quais as avaliações são baseadas em provas escritas, na nova implementação os alunos são avaliados considerando seus respectivos desempenhos nas provas escritas e em todas as demais atividades realizadas ao longo do curso.

Essas mudanças representam uma guinada em direção a uma abordagem na qual o aluno deve apresentar um comportamento mais ativo no seu processo de aprendizagem, sendo o responsável por interagir com o conhecimento de forma mais autônoma e crítica. Além das mudanças metodológicas, as novas turmas são também compostas por alunos dos diferentes cursos do campus, possibilitando o compartilhamento de experiências entre as diferentes populações de alunos e enriquecendo as discussões na sala de aula.

Essa nova proposta foi bem recebida e acolhida pela maioria dos cursos do campus, mas como no primeiro oferecimento nem todos os cursos haviam ainda aderido à proposta, surgiu a oportunidade de uma situação propí- 
cia para se aplicar, em larga escala, o FCI nas disciplinas de Física 1 do campus de São Carlos, podendo comparar resultados das duas abordagens. Dessa maneira, buscamos avaliar o impacto dessas abordagens distintas no ganho conceitual dos alunos brasileiros. Outro aspecto interessante se refere ao fato desses estudantes terem passado por um processo seletivo rigoroso e concorrido para o ingresso na Universidade. A literatura sugere que isso possa estar relacionado com o desempenho desses alunos, quando comparados à alunos cuja seleção seja menos rigorosa [4]. Apresentamos aqui resultados que parecem confirmar essa hipótese.

Dessa maneira, o presente trabalho avaliou o ganho conceitual de Física básica, relacionado conceitos de mecânica Newtoniana, de alunos de graduação dos cursos iniciais de ciência, matemática e engenharias que cursaram disciplinas de formação ministradas utilizando metodologias de ensino convencional e metodologias ativas. Com isso, quantificou-se o limiar conceitual em que os alunos se encontravam no ingresso do curso, traçou-se seus perfis conceituais e, ao aplicar novamente o teste no fim do semestre, observou-se o impacto que as aulas tiveram nesses respectivos perfis. Os resultados obtidos são avaliados e comparados com os resultados nacionais e internacionais da literatura.

\section{Materiais e métodos}

O presente trabalho foi realizado no Instituto de Física de São Carlos da Universidade de São Paulo (IFSC/USP), em parceria com os professores responsáveis pelas disciplinas analisadas.

\subsection{Instrumento}

As concepções conceituais em Mecânica Newtoniana foram avaliadas utilizando o questionário $F C I$ [3], discutido na introdução. Foi utilizada a versão traduzida e validada em Português, disponibilizada pelos próprios proponentes do questionário através de um acordo de manutenção de confidencialidade com o professor responsável pelo presente estudo. O instrumento é composto por 30 questões de múltipla escolha que deve ser respondido em um período de 20 a 30 minutos. Neste estudo, foi adotado o tempo de 30 minutos para a resolução do questionário.

\subsection{Coleta de Dados}

Toda a coleta de dados foi feita com a anuência dos docentes presentes em sala de aula no momento da coleta e concordância dos estudantes, que participaram de forma voluntária. Foram realizadas duas coletas de dados ao longo do primeiro semestre de curso: a primeira coleta foi realizada na primeira semana de aula do curso, o que permitiu determinar as linhas de base da frequência de acerto das questões para cada um dos participantes; a segunda aplicação foi feita ao final do semestre, próximo do fim da disciplina, em data definida juntamente com o docente da disciplina de maneira a não comprometer o andamento do curso.

\subsection{Sujeitos}

Os questionários foram aplicados aos alunos ingressantes dos cursos de graduação do campus de São Carlos da Universidade de São Paulo, matriculados nas disciplinas de Física 1, oferecido pelo IFSC/USP aos diversos cursos do campus. Participaram do estudo um total de 599 alunos de 14 turmas. A maioria dos alunos são ingressantes (calouros), no primeiro ano da universidade. As turmas foram classificadas como TRADICIONAL (T) para aquelas que não participaram da nova estruturação dos cursos e INTEGRADA (INT) para as turmas que fazem parte do novo programa para as disciplinas de Física Básica. Os cursos de ingresso dos alunos foram nomeados como C-01 até C-13, de forma aleatória, sem seguir qualquer ordem sequencial com relação aos cursos listados a seguir. Os cursos incluídos nesta pesquisa são: Bacharelado em Ciências Físicas e Biomoleculares, Bacharelado em Física, Bacharelado em Física Computacional, Bacharelado em Matemática, Engenharia Aeronáutica, Engenharia Ambiental, Engenharia Civil, Engenharia de Computação, Engenharia Elétrica, Engenharia de Materiais, Engenharia Mecânica, Engenharia Mecatrônica e Engenharia de Produção.

Do total de participantes, 365 alunos responderam à segunda aplicação do questionário, participando de todas as etapas do estudo. Essa diminuição no número de respondentes na segunda aplicação se deve a fatores diversos. O primeiro fator está relacionado ao momento da primeira aplicação, que é feita na primeira semana do curso para evitar que as primeiras aulas comprometam a avaliação da linha de base. Nesse momento, as turmas ainda não estão completas e ainda existe uma grande movimentação dos alunos, incluindo alguns que são chamados em outras unidades ou instituições em chamadas tardias e que acabam deixando o curso no qual foram avaliados inicialmente. Além disso, ao longo do semestre existem os alunos que trancam ou desistem da disciplina. Finalmente, como a aplicação do questionário (tanto a primeira como a segunda) é feita em uma única aula, o aluno que não se encontra presente no dia da aplicação acaba por não participar da segunda etapa do estudo. Do ponto de vista do estudo, isso não representa um problema uma vez que o número de respondentes ainda é compatível com as análises a serem realizadas, não comprometendo, portanto, as conclusões obtidas.

\subsection{Critérios de Inclusão}

- Ser aluno regularmente matriculado em um curso de graduação oferecido pela Universidade de São Paulo;

- Ser aluno regularmente matriculado na disciplina de Física I oferecida pelo IFSC/USP, no ano de 2017 ; 
- Concordar em ter seus resultados utilizados na pesquisa.

\subsection{Análise dos Dados}

Todos os dados foram submetidos à análise considerando os cursos de ingresso dos alunos, além da turma em que estavam matriculados.

O ganho percentual normalizado para cada aluno e turma foi determinado conforme definido por Hake [7]:

$$
<g>=\frac{G}{100 \%-S_{\text {pré }}}
$$

Onde $\langle g\rangle$ representa o ganho conceitual normalizado e $G$ representa o ganho conceitual simples, calculado por:

$$
G=S_{\text {pós }}-S_{\text {pré }}
$$

Os valores de $S_{\text {pré e }} S_{\text {pós }}$ são apresentados em porcentagem de acertos nas respectivas aplicações do questionário. Para a visualização da dispersão dos dados de Ganho Normalizado das turmas, construiu-se o gráfico do Ganho Percentual Simples contra o percentual de acertos no PréTeste $\left(S_{\text {pré}}\right)$. Desse modo, as turmas foram categorizadas mais facilmente de acordo com a proposição feita por Hake [4]:

- "Alto ganho", para turmas com $\langle g\rangle \geq 0,7$;

- "Médio ganho", para turmas com $0,7><g>\geq$ 0,3

- "Baixo ganho", para turmas com $<g\rangle<0,3$.

Análises de correlação foram realizadas utilizando o teste de Pearson e os valores foram considerados significativos para um valor de $\mathrm{p}<0,05$.

\section{Resultados e discussões}

\subsection{Pré-Teste}

As Tabelas 1 e 2 mostram os resultados obtidos no préteste dos participantes do estudo, separados por curso de ingresso e por turma. São apresentados, ainda, o número de respondentes por curso e por turma, e a respectiva nota de corte para ingresso (vestibular) nos cursos avaliados [25].

Observa-se que, para a aplicação inicial do questionário, o número mínimo de alunos entre os 13 cursos participantes da pesquisa foi de 30 e o número máximo de 90, com variações entre os cursos, totalizando 599 respondentes no Pré-Teste. Entre as turmas, o número mínimo de alunos foi 31 e o máximo de 60. Esta amostra, tanto considerando o agrupamento por cursos como por turmas, nos garante robustez estatística para a posterior análise dos resultados.

Com exceção do curso C-13, todos os outros cursos obtiveram resultados médios iniciais superiores a 50\%, com a grande maioria situada na faixa de $60-80 \%$, considerada pelos propositores do questionário como o "limiar de entrada" do pensamento Newtoniano. Já os cursos C-06 e C-08, que obtiveram resultados médios de $81 \%$ e $82 \%$ na aplicação do Pré-Teste, respectivamente, encontram-se próximos ao "limiar de domínio" do pensamento Newtoniano.

Tabela 2: Descrição da amostra de respondentes por turma e o respectivo desempenho médio na aplicação inicial do questionário.

\begin{tabular}{lcc}
\hline Turma & Número de Alunos & $\mathbf{S}_{\text {pré }}(\%)(\mathbf{D P})$ \\
\hline T-1 & 42 & $81(16)$ \\
T-2 & 60 & $70(18)$ \\
T-3 & 47 & $60(17)$ \\
T-4 & 53 & $76(16)$ \\
T-5 & 37 & $55(19)$ \\
T-6 & 33 & $45(26)$ \\
INT-1 & 39 & $68(24)$ \\
INT-2 & 54 & $56(21)$ \\
INT-3 & 48 & $78(20)$ \\
INT-4 & 44 & $69(23)$ \\
INT-5 & 31 & $69(25)$ \\
INT-6 & 38 & $75(18)$ \\
INT-7 & 41 & $65(20)$ \\
INT-8 & 32 & $73(14)$ \\
\hline DP: desvio padrão. & &
\end{tabular}

Tabela 1: Descrição da amostra de respondentes por curso de ingresso, incluindo a respectiva nota de corte para ingresso de cada um dos cursos, e o desempenho médio dos mesmos na aplicação inicial do questionário.

\begin{tabular}{lccc}
\hline Curso & Número de Alunos & Nota de Corte & $\mathbf{S}_{\text {pré }}(\%)(\mathbf{D P})$ \\
\hline C-01 & 31 & 41 & $69(21)$ \\
C-02 & 30 & 41 & $62(22)$ \\
C-03 & 46 & 44 & $52(23)$ \\
C-04 & 90 & 51 & $70(20)$ \\
C-05 & 38 & 54 & $72(15)$ \\
C-06 & 42 & 54 & $81(16)$ \\
C-07 & 51 & 51 & $75(19)$ \\
C-08 & 41 & 62 & $82(17)$ \\
C-09 & 60 & 55 & $70(18)$ \\
C-10 & 37 & 44 & $55(19)$ \\
C-11 & 47 & 45 & $60(17)$ \\
C-12 & 53 & 41 & $76(16)$ \\
C-13 & 33 & & $45(26)$ \\
\hline DP. desvio padrão & &
\end{tabular}


Podemos comparar nossos resultados com os de Hake [7], Barros et al. [5] e Goya et al. [6] e observamos que as médias da nossa amostra são superiores às encontradas nos referidos estudos para a aplicação do Pré-Teste em alunos dos cursos introdutórios de Física e comparáveis aos resultados de turmas avançadas de universidades de alto prestígio da América Latina, Estados Unidos e Espanha, como mostrado por Artomónova et al. [4].

Como assinalado por Artomónova et al. [4], o grupo de universidades que se destacou com altos resultados iniciais no FCI são consideradas universidades criteriosas na seleção de seus alunos, como ocorre no processo seletivo da USP, organizado pela Fundação Universitária para o Vestibular (FUVEST), que tradicionalmente é conhecido como um dos processos seletivos mais concorridos do país.

A Figura 1 mostra a relação entre os resultados do Pré-Teste e a nota de corte para a admissão à segunda fase do vestibular. Pode-se notar uma tendência dos resultados do Pré-Teste $\left(S_{\text {pré}}\right)$ do FCI aumentarem à medida que as notas de corte dos cursos também aumentam. O coeficiente de correlação Pearson obtido mostra uma significativa correlação positiva $(\rho=0,81, \mathrm{p}<0,001)$ entre a concorrência para o ingresso no curso de graduação pelo vestibular da FUVEST e o conhecimento dos estudantes dos conceitos da Mecânica Newtoniana avaliados pelo FCI.

Para analisar o impacto das diferentes metodologias no perfil conceitual dos alunos, optou-se por estudar os resultados em relação às turmas em que se encontravam matriculados durante o semestre letivo e não em relação aos seus respectivos cursos de ingresso. Isso é particularmente importante para o caso das turmas integradas, onde diversos cursos estão presentes na mesma sala. A Figura 2 apresenta a porcentagem de estudantes de cada turma que obteve acertos no Pré-Teste agrupados em intervalos de $20 \%$, partindo do intervalo 0-20\% em diante,

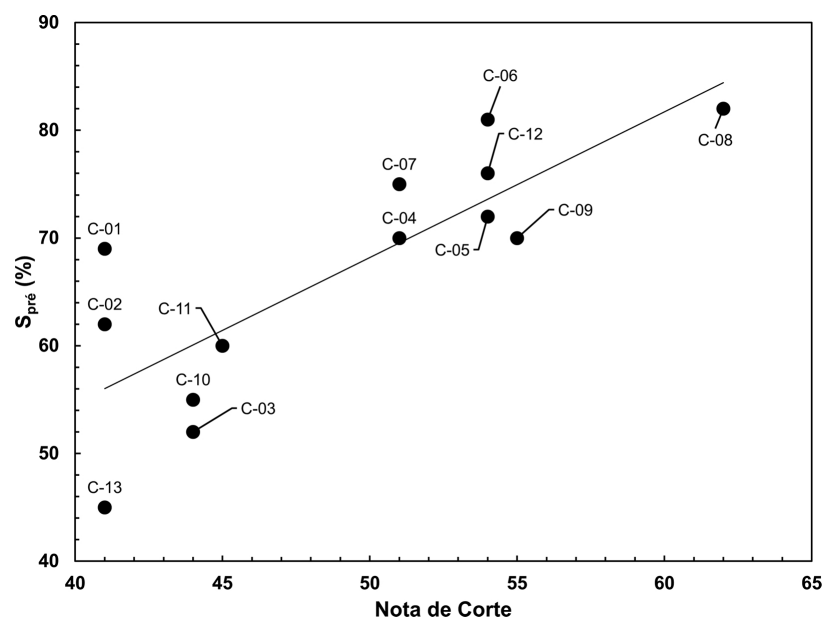

Figura 1: Nota média obtida no pré-teste $\left(S_{\text {pré}}\right)$ pelos alunos dos cursos avaliados em função de suas respectivas notas de corte para ingresso. criando dessa maneira uma caracterização do perfil conceitual das turmas no momento de início da disciplina na universidade. $\mathrm{O}$ eixo horizontal representa as diferentes turmas estudadas, a altura da barra representa a porcentagem de alunos de cada turma referente ao intervalo de acertos analisado e por fim as diferentes cores que preenchem as colunas representam as faixas de porcentagem de acerto, separadas em intervalos de $20 \%$, dos alunos no Pré-Teste.

Podemos destacar as turmas T-1 e INT-3, que apresentam, respectivamente, $60 \%$ e $50 \%$ dos alunos integrantes com resultados acima de $80 \%$ de acertos no Pré-Teste. Notamos também que a porcentagem de alunos que obteve resultados menores que $20 \%$, de maneira geral, é pequena para todas as turmas, sendo que a maior concentração dos alunos se encontra nos intervalos de $61-80 \%$ e 81-100\%, o que confirma a posição de destaque dos resultados obtidos pela média dos cursos apresentados anteriormente e comparados com os resultados analisados por Artomónova et al. [4], destacando a posição de prestígio da USP no contexto da América Latina.

\subsection{Pós-Teste}

No momento da segunda aplicação do questionário FCI, realizada ao final do semestre letivo e aqui tratada como Pós-Teste, tivemos a participação de 365 alunos e, apesar da diminuição no número de respondentes, nossas conclusões não são afetadas pois todas as análises comparativas, relativas ao ganho conceitual, são feitas apenas com esses alunos, relacionando seu desempenho anterior com o posterior. A Tabela 3 mostra os resultados obtidos no Pós-teste dos participantes do estudo, separados

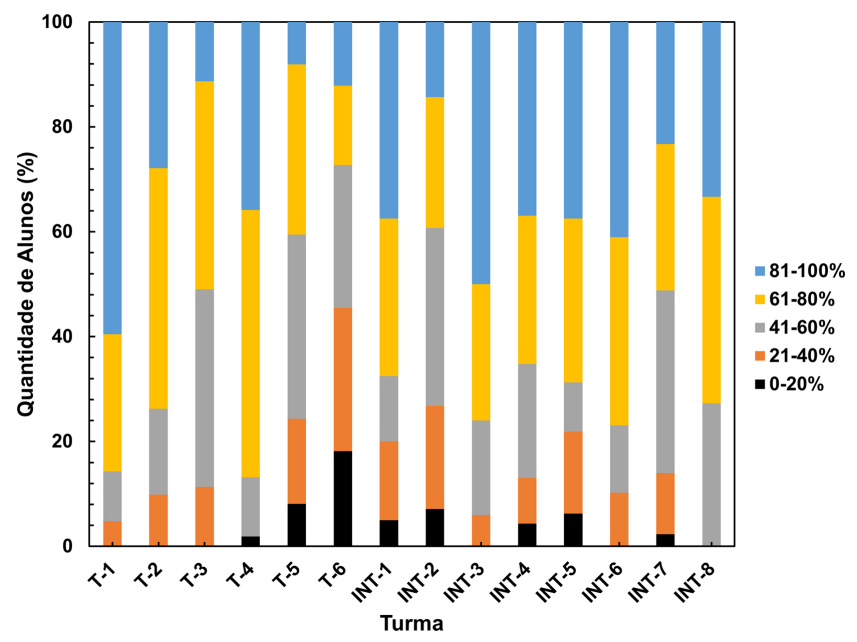

Figura 2: Quantidade percentual de alunos das turmas que atingiram pontuação em cada um dos intervalos definidos no préteste. Foram definidos 5 intervalos de $20 \%$ cada. O eixo horizontal representa as diferentes turmas estudadas, a altura da barra representa a porcentagem de alunos de cada turma referente ao intervalo de acertos analisado e, por fim, as diferentes cores que preenchem as colunas representam as faixas de porcentagem de acerto no Pré-Teste. 
por turma. De maneira a entender a evolução do perfil conceitual dos alunos com relação às diferentes metodologias, construímos o gráfico mostrado na Figura 3, que apresenta os resultados do Pós-Teste comparado ao Pré-Teste.

A linha representa a reta de coeficiente angular unitário, ou seja, os pontos que se localizam exatamente sobre a linha apresentam resultados no Pré- e no Pós-Teste idênticos $\left(S_{\text {pré }}=S_{\text {pós }}\right)$, o que corresponde a um ganho conceitual nulo. Já os pontos abaixo da linha, pela definição acima, apresentam resultados do Pós-Teste menores que o Pré-Teste $\left(S_{\text {pós }}<S_{\text {pré }}\right)$, resultando num ganho conceitual negativo. De maneira análoga, os pontos acima da linha representam aquelas turmas que obtiveram resultados no

Tabela 3: Desempenho médio na aplicação final do questionário e os respectivos ganhos normalizados médios das turmas.

\begin{tabular}{lll}
\hline Turma & $\mathbf{S}_{\mathbf{p o ́ s}}(\%)(\mathbf{D P})$ & $<\mathbf{g}>$ \\
\hline T-1 & $85(13)$ & 0,25 \\
T-2 & $72(16)$ & 0,10 \\
T-3 & $61(20)$ & 0,07 \\
T-4 & $86(10)$ & 0,36 \\
T-5 & $56(18)$ & 0,00 \\
T-6 & $61(20)$ & 0,36 \\
INT-1 & $79(19)$ & 0,38 \\
INT-2 & $76(19)$ & 0,43 \\
INT-3 & $89(11)$ & 0,45 \\
INT-4 & $85(13)$ & 0,52 \\
INT-5 & $81(18)$ & 0,30 \\
INT-6 & $85(14)$ & 0,40 \\
INT-7 & $76(21)$ & 0,23 \\
INT-8 & $82(27)$ & 0,33 \\
\hline DP: & &
\end{tabular}

DP: desvio padrão.

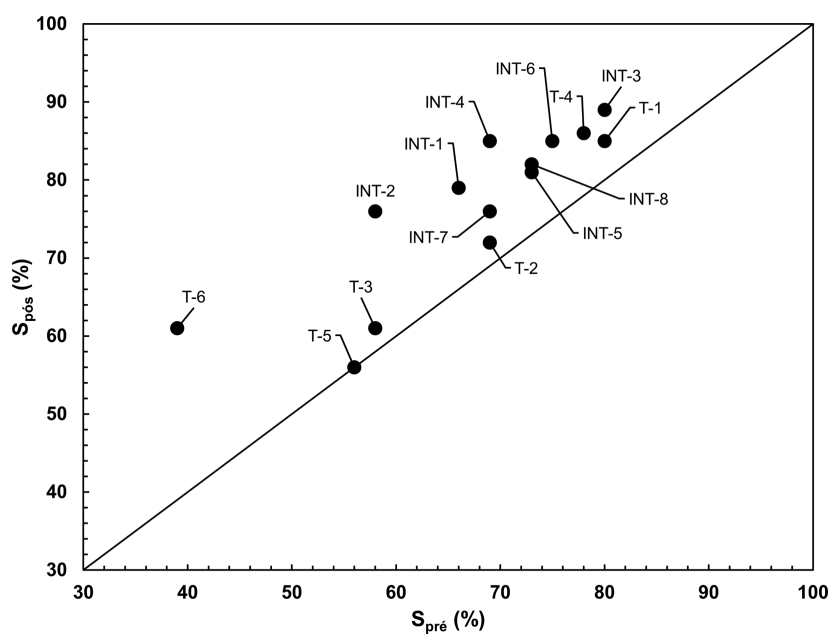

Figura 3: Nota média obtida no pós-teste $\left(S_{\text {pós }}\right)$ comparada com a nota média obtida no pré-teste $\left(S_{\text {pré}}\right)$ pelos alunos das turmas avaliadas. A linha representa a reta de coeficiente angular unitário, ou seja, os pontos que se localizam exatamente sobre a linha apresentam resultados no Pré-Teste idênticos ao Pós-Teste ( $S_{\text {pré }}=S_{\text {pós }}$ ), o que corresponde a um ganho conceitual nulo. Já os pontos os pontos acima da linha representam aquelas turmas que obtiveram resultados no Pós-Teste maiores que os do Pré-Teste ( $S_{\text {pós }}>S_{\text {pré}}$ ), ou seja, tiveram ganho conceitual positivo.
Pós-Teste maiores que os do Pré-Teste $\left(S_{\text {pós }}>S_{\text {pré }}\right)$, ou seja, tiveram ganho conceitual positivo.

Apenas uma das 14 turmas avaliadas (T-5) localizouse na região exatamente em cima da linha, indicando que, na média, não houve ganho conceitual ao final do semestre. O restante das turmas avaliadas encontra-se acima da linha. Tal fato nos indica que independente da metodologia adotada (tradicional ou ativa), o ganho conceitual foi positivo ou nulo. Em relação à magnitude do ganho, com exceção das turmas T-6 e T-4, que se encontram em uma região entre as turmas integradas, todas as outras turmas tradicionais se encontram mais próximas à linha de coeficiente angular unitário, o que nos revela que estas turmas, apesar de terem obtido resultados positivos para o ganho conceitual simples, seus resultados no Pós-Teste foram muito próximos ao do Pré-Teste.

As turmas T-6 e INT-2 são as turmas que apresentam maior ganho conceitual simples, calculado pela equação 2 , dentre as turmas estudadas, sendo iguais a $22 \%$ e $18 \%$, respectivamente. Este é um dado interessante pois nos revela que, apesar de fazer parte de uma turma submetida à metodologia tradicional de ensino, a turma T-6 teve, na média, um aumento no rendimento do teste que superou as turmas integradas, o que não é comum na literatura especializada [7]. Por outro lado, é importante observar que essa turma apresentou um desempenho muito baixo no Pré-Teste e, mesmo com alto ganho, no final atingiu apenas o limiar inferior dos conceitos Newtonianos, permanecendo bem abaixo do resultado de todas as turmas Integradas.

Isso levanta um ponto interessante no que se refere à interpretação de dados obtidos utilizando o FCI. Levar em conta apenas o ganho simples, muitas vezes mascara parte da informação presente nos dados. Um exemplo seria um aluno (ou uma turma inteira) que acertasse $100 \%$ das questões na aplicação inicial. Isso daria origem a uma situação em que, na melhor das hipóteses, teríamos ganho nulo no caso de uma segunda aplicação. Pequenas flutuações, entretanto, poderiam, inclusive, gerar ganho negativo.

Analisando a Figura 2, pode-se ver que as turmas T-6 e INT-2 são aquelas que apresentaram menor incidência de alunos atingindo a pontuação necessária para ocupar o último quintil ( $80 \%$ a $100 \%)$. Isso significa que um percentual grande de alunos dessas turmas ainda tinha possibilidade de melhorar bastante seu desempenho. Na turma T-6, por exemplo, quase $90 \%$ da turma obteve resultados abaixo de $60 \%$ na aplicação do Pré-Teste. Por outro lado, a turma T-1, por exemplo, que apresentou ganho não muito expressivo, possuía aproximadamente metade dos seus alunos já com pensamento Newtoniano, o que limita o potencial de ganho médio da turma como um todo, uma vez que apenas uma parcela pequena dos alunos é capaz de contribuir com ganho significativo independente da qualidade e eficiência do curso. 
Novamente, para uma melhor análise do impacto das diferentes metodologias no perfil conceitual das turmas, apresentamos na Figura 4 gráficos mostrando a incidência percentual de alunos em cada um dos quintis definidos anteriormente. Os dados do Pré-Teste foram incluídos novamente nos gráficos, pois, como mencionado, nesse caso são considerados apenas os alunos que responderam às duas aplicações do questionário.

Dos alunos das turmas tradicionais que participaram tanto do Pré-Teste como do Pós-Teste podemos observar, a partir da Figura 4a, que com exceção das turmas T-5 e T-6, o número de alunos que acertou entre $81-100 \%$ entre as duas aplicações consecutivas do FCI aumentou de forma significativa, com destaque para as turmas T-1 e T-4, que passaram de $50 \%$ para $75 \%$ e $33 \%$ para $60 \%$, respectivamente, no número de alunos com resultados
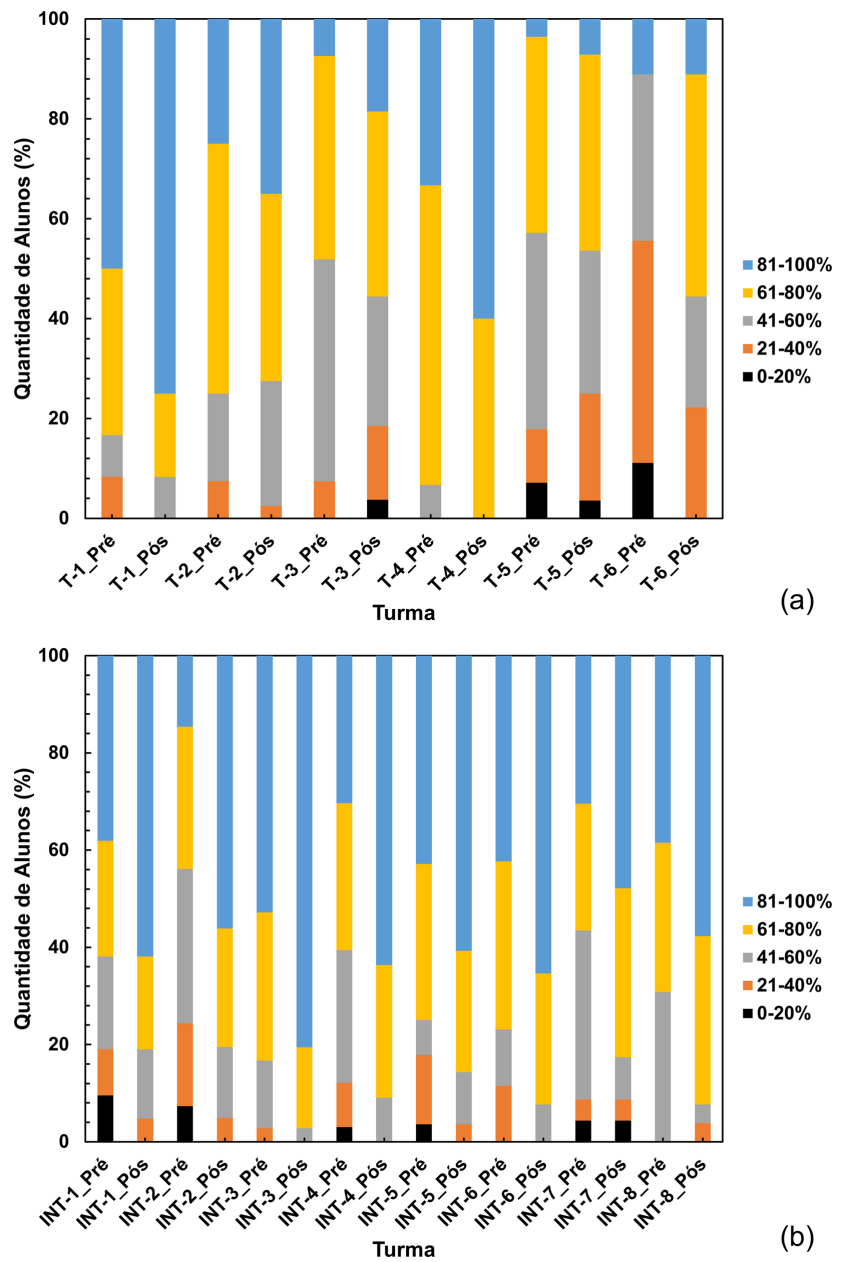

Figura 4: Quantidade percentual de alunos das turmas que atingiram pontuação em cada um dos intervalos definidos no pré-teste e no pós-teste. Foram definidos 5 intervalos de $20 \%$ cada. O eixo horizontal representa as diferentes turmas estudadas, a altura da barra representa a porcentagem de alunos de cada turma referente ao intervalo de acertos analisado e, por fim, as diferentes cores que preenchem as colunas representam as faixas de porcentagem de acerto no Pré- e no Pós-Teste. (a) Turmas tradicionais. (b) Turmas integradas. superiores a $81 \%$ de acertos no questionário. Já a turma T-6, que não tinha nenhum aluno, dos que responderam a ambas as aplicações do questionário, no intervalo de $61-80 \%$, terminou o semestre com $44 \%$ dos alunos nessa faixa. De maneira geral, nota-se uma evolução global em todas as turmas avaliadas, com aumento geral no número de alunos para o nível de "domínio" dos conceitos Newtonianos.

De maneira análoga, podemos olhar para o perfil das turmas Integradas e observar que todas as turmas, com exceção da turma INT-7, tiveram mais de $50 \%$ dos seus alunos com resultados superiores a $80 \%$ no Pós-Teste (Figura 4b). Também podemos considerar significativa a redução no número de alunos que tiveram resultados abaixo de $60 \%$. Considerando todas as turmas Integradas, o percentual de alunos abaixo do limiar de entrada do pensamento Newtoniano esteve sempre abaixo de $20 \%$, com média global de $12 \%$. Já no caso das turmas Tradicionais, algumas chegaram a apresentar mais de $50 \%$ dos alunos abaixo desse limiar ao final do semestre, com média geral de $30 \%$.

Agora, para melhor compararmos nossos resultados com os de pesquisas que utilizam o FCI como método avaliativo do impacto de metodologias no ensino de Física, utilizaremos o conceito de Ganho Conceitual Normalizado, definido pela equação (1). Os valores médios obtidos para cada uma das turmas estão listados na Tabela 3. De maneira similar à de Hake [7], foi construído um gráfico do ganho simples em função do desempenho na aplicação inicial do questionário (Figura 5). Dessa maneira, podemos dividir o gráfico em 3 regiões distintas delimitadas pelas retas de coeficiente angular $\alpha_{1}-0,3$ (reta inferior) e $\alpha_{2}-0,7$ (reta superior). Turmas situadas na região abaixo da reta com coeficiente angular $\alpha_{1}$ se encontram na faixa de "Baixo Ganho Conceitual". Analogamente, turmas situadas na região entre as duas retas auxiliares são consideradas na faixa de "Médio Ganho Conceitual". Por fim, a região acima da reta superior, é considerada de "Alto Ganho Conceitual".

Analisando a Figura 5, pode-se observar que, com exceção da turma INT-7, todas as turmas Integradas encontram-se na região de médio ganho conceitual. Considerando as turmas Integradas, a média global de acertos no Pré-Teste foi de 70,4\%, enquanto que ao final do curso, os alunos atingiram média de $81,6 \%$ de acertos, representando um ganho normalizado médio de 0,38.

Entre as turmas Tradicionais, como já mencionado, a turma T-6 merece destaque por ter se situado na região de médio ganho conceitual, junto com a turma T-4, que ficou no limiar inferior dessa mesma região. As demais, entretanto, localizaram-se na região de baixo ganho conceitual. Nesse caso, a média de acertos na aplicação inicial foi de $63,3 \%$, enquanto o valor no final do semestre chegou a $70,2 \%$, em média. Isso representa um ganho normalizado médio de 0,19, ou seja, aproximadamente metade do valor obtido pelas turmas com metodologias ativas. Portanto, este estudo confirma, mais uma vez, o 


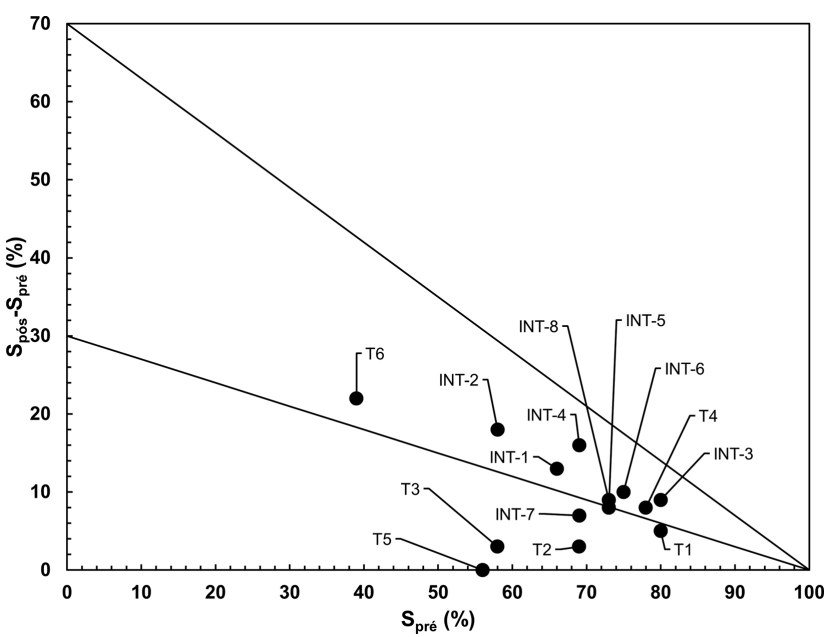

Figura 5: Distribuição dos ganhos percentuais médios de cada uma das turmas pelo percentual médio de acertos no Pré-Teste $\left(S_{\text {pré }}\right)$. Considerando todas as turmas integradas, o ganho normalizado médio foi $\langle\mathrm{g}\rangle=0,38$. Já para as turmas tradicionais, o valor médio foi de $\langle\mathrm{g}\rangle=0,19$.

principal resultado da literatura internacional em PER, de que disciplinas baseadas em estratégias de metodologias ativas são mais eficientes no ensino de conceitos físicos do que as metodologias tradicionais. Vale destacar, que este é o primeiro estudo sistemático em larga escala realizado numa grande universidade pública brasileira na literatura especializada nacional.

Nota-se, porém, que nenhuma turma, seja Integrada ou Tradicional, se encontra na região de Alto Ganho Conceitual. Uma hipótese para isso é o fato de que o perfil conceitual inicial dos alunos ao ingressarem na universidade já se localiza, majoritariamente, nas regiões denominadas de "entrada" ou de "domínio" dos conceitos Newtonianos, e como afirmado por Hestenes et al. [3], quanto maior o resultado no Pré-Teste, ou seja, quanto maior o conhecimento dos conceitos Newtonianos no momento de ingresso na universidade, mais dificilmente se observará um grande impacto da disciplina no pensamento Newtoniano do estudante, ao realizar o Pós-Teste. Em outras palavras, o Ganho Conceitual final fica limitado quando o resultado inicial do Pré-teste já é bem alto, devido à pequena margem disponível para crescimento. Essa é uma limitação da metodologia utilizada nesse tipo de teste e algo que deve ser analisado com mais cuidado no futuro.

\section{Conclusão}

Destoando dos resultados encontrados na recente literatura de aplicação do FCI na América Latina e outros países, os alunos analisados neste estudo obtiveram notas altas logo na primeira aplicação do FCI, com a maioria dos estudantes com médias superiores a $60 \%$ de acertos no questionário. Uma análise inicial sugere que isso pode estar relacionado ao processo seletivo pelo qual os alunos passam para ingressar na Universidade de São Paulo, neste caso o vestibular da FUVEST, historicamente reconhecido como um exame concorrido e exigente. Verificamos uma correlação positiva entre as notas de corte dos cursos e as notas no Pré-Teste, sugerindo que devido à alta concorrência do processo seletivo, o aluno regular ingressante nos cursos de exatas da USP inicia seus estudos já com ideias formadas sobre os conceitos da Mecânica Newtoniana, muitas vezes já "iniciado" na linguagem e familiar com os conceitos. Esse resultado indica que as disciplinas de física básica devem ser moldadas e executadas de modo a favorecer o enriquecimento destes conceitos ao longo do semestre, com o objetivo de tentar aproximá-los o máximo possível do "limiar de domínio". Essa é uma informação relevante no planejamento didático dessas disciplinas introdutórias de Física, pelo menos no caso do perfil da população de estudantes atendidos pela USP.

Uma consequência importante das características observadas neste estudo é que o ganho conceitual médio normalizado das disciplinas avaliadas não atingiu o patamar mais alto possível, talvez devido à alta performance dos estudantes observada no Pré-Teste. No entanto, os resultados do Pós-Teste mostram que as turmas obtiveram desempenhos compatíveis com os resultados das demais pesquisas internacionais. Em particular, nossos dados mostram que as turmas com metodologias de aprendizagem ativa obtêm, de maneira geral, resultados superiores ao de turmas com metodologias tradicionais, indicando que disciplinas bem estruturadas e engajadas em metodologias educacionais baseadas em pesquisa resultam em um melhor desempenho conceitual dos alunos ao final do semestre $(<g>=0,38)$, com significativa vantagem em comparação às turmas com metodologia tradicional $(<g\rangle=0,19)$. Esses resultados são comparáveis aos trabalhos realizados com engajamento ativo em outras universidades $[5,7]$.

Em suma, este trabalho contribui no sentido de oferecer dados para a literatura nacional que verificam, em larga escala, que a mudança para metodologias de aprendizagem ativa influencia de maneira positiva o aprendizado conceitual dos alunos. Futuros trabalhos deverão avaliar se esse comportamento se mantém independente das turmas avaliadas e, principalmente, se esse aumento no desempenho conceitual se reflete no desempenho em avaliações tradicionalmente utilizadas no Ensino Superior na área de exatas, particularmente as provas escritas, baseadas na resolução de problemas. Isso poderá contribuir ainda mais para a discussão acerca dos métodos avaliativos mais adequados e abrangentes, bem como para o aprimoramento das melhores estratégias de ensino para nossos estudantes.

\section{Agradecimentos}

Ao Instituto de Física de São Carlos da Universidade de São Paulo, especialmente sua Comissão de Graduação, 
aos docentes responsáveis pelas turmas avaliadas, por todo suporte, e aos estudantes que aceitaram participar da pesquisa. Além disso, gostaríamos de agradecer à Universidade de São Paulo que, através do Programa Unificado de Bolsas de Estudo (Proj. PUB 1823/2017), financiou o presente estudo.

\section{Referências}

[1] I.A. Halloun e D. Hestenes, American Journal of Physics 53, 1043 (1985).

[2] I.A. Halloun e D. Hestenes, American Journal of Physics 53, 1056 (1985).

[3] D. Hestenes, M. Wells e G. Swackhamer, The physics teacher 30, 141 (1992).

[4] I. Artamonova, J.C. Mosquera-Mosquera e J.D. Mosquera-Artamonov, Revista Educacion En Ingenieria 12, 56 (2017).

[5] J.A. Barros, J. Remold, G.S.F. Silva e J.R. Tagliati, Revista Brasileira de Ensino de Física 26, 63 (2004).

[6] A. Goya e C.E. Laburu, Experiências em Ensino de Ciências 9, 32 (2014).

[7] R.R. Hake, American Journal of Physics 66, 64 (1998).

[8] L.C. McDermott e E.F. Redish, American Journal of Physics 67, 755 (1999).

[9] D.E. Meltzer e R.K. Thornton, American Journal of Physics 80, 478 (2012).

[10] J.E. Parreira, Revista Brasileira de Ensino de Física 40, e1401 (2018).

[11] A. Savinainen e P. Scott, Physics Education 37, 53 (2002).

[12] A. Savinainen e P. Scott, Physics Education 37, 45 (2002).

[13] A.M. Lopes, Combinando metodologia de ensino peer instruction com just-in-time para ensino de física. Dissertação de Mestrado, Universidade Federal de Viçosa, Viçosa (2016).

[14] E. Mazur, Peer Instruction: A User's Manual (Prentice Hall, New Jersey, 1997).

[15] S. Freeman, S.L. Eddy, M. McDonough, M.K. Smith, N. Okoroafor, H. Jordt e M.P. Wenderoth, Proceedings of the National Academy of Sciences of the United States of America 111, 8410 (2014).

[16] C.E. Wieman, Proceedings of the National Academy of Sciences of the United States of America 111, 8319 (2014).

[17] P. Heller e D. Huffman, The physics teacher 33, 503 (1995).

[18] D. Hestenes e I.A. Halloun, The physics teacher 33, 502 (1995).

[19] D. Huffman e P. Heller, The physics teacher 33, 138 (1995).

[20] A. Savinainen e J. Viiri, International Journal of Science and Mathematics Education 6, 719 (2008).

[21] M.D. Caballero, E.F. Greco, E.R. Murray, K.R. Bujak, M.M. Jackson, R. Catrambone e M.F. Schatz, American Journal of Physics 80, 638 (2012).

[22] R.J. Dufresne, W.J. Gerace, W.J. Leonard, J.P. Mestre e L. Wenk, Journal of Computing in Higher Education 7, 3 (1996).
[23] D.J. Nicol e J. T. Boyle, Studies in Higher Education 28, 457 (2003)

[24] J. Bergmann e A. Sams, Flip your classroom: Reach every student in every class every day (International Society for Technology in Education, Washington, 2012).

[25] acervo.fuvest.br/fuvest/2017/fuv2017_corte.pdf. 